\title{
TLC-Based Enantiomeric Separation of Amino Acids onto $\beta$-CD-Incorporated Glutaraldehyde-Crosslinked PVA Electrospun Fiber Stationary Phase
}

\author{
Sahrish Khatri ${ }^{1}$, Najma Memon ${ }^{1 *}$, Zeeshan Khatri ${ }^{2}$ and Farooq Ahmed ${ }^{2}$ \\ ${ }^{\prime}$ National Centre of Excellence in Analytical Chemistry, University of Sindh, Jamshoro \\ ${ }^{2}$ Nanomaterial Research Group, Department of Textile Engineering, Mehran University of Engineering and Technology, Jamshoro, Pakistan
}

Received: 25 Jul 2019; accepted: 26 Jul 2019

\begin{abstract}
Simple and economical methods for chiral separations are always needed in synthesis and drug development and as biomarkers, besides many other useful applications. Cyclodextrins (CDs) are chiral host molecules and have been used to separate a number of chiral analytes. In this study, we have successfully prepared electrospun films of $\beta$ CD incorporated into polyvinyl alcohol (PVA) through glutaraldehyde (GA) crosslinking. These films of $\beta$-CDPVA-GA electrospun fibers are characterized by Fourier transform infrared (FTIR) and scanning electron microscopy (SEM), which were subsequently used for thin-layer chromatography (TLC)-based enantiomeric separation of histidine and serine pairs. Amino acids were detected by spraying the chromatograms with the ninhydrin solution. Among various solvent systems employed, it was found that the separation of serine enantiomers with a resolution of 1.6 was possible with the mobile phase ethanol-butanol-ethyl acetate-water-acetone (4:5:5:0.5:1.5, v/v), and histidine enantiomers with a resolution of 1.4 were possible with the mobile phase ethanol-butanol-ethyl acetatewater-acetone $(4: 5: 4.5: 0.5: 1.5, v / v)$. This proves that the prepared stationary phase is efficient in enatioresolution of selected amino acid pairs and can be further examined for physiological samples.
\end{abstract}

Keywords: chiral thin-layer chromatography, electrospun fibers, chiral stationary phases

\section{Introduction}

Chiral compounds can be found as natural products and have important biological activities. All chiral molecules contain asymmetric center, which have been of an important consideration for many compounds [1]. Chiral isomeric compounds possess different physical and chemical properties and therefore show dissimilar biological actions. Amino acids have two main groups, a carboxyl and an amino group, and possess asymmetric carbon, which is bonded to 4 different atoms attached covalently [2]. Because of this behavior amino acids have extremely dissimilar biochemical function and properties [3]. Moreover, D-amino acids being seldom found in the higher animals, L-amino acids are present largely with different physiological functions in the body [4]. Consequently all the metabolic products are also in L-form. Certainly, in nature, D-amino acids also exist and play some biochemical roles, but they are never found in protein [5]. Recently, D-amino acids were reported in human biological samples at some stages in certain neurological disorders [6]. In human tissues and biofluids, anomalous quantities of D-amino acids were accounted for their association with the diseases, like schizophrenia [7], Alzheimer [8], and chronic renal failure [9]. In mammals, the presence of D-serine and D-aspartic acid is associated with significant physiological functions, while in brain disorders, free D-serine is detected [10].

Further research is aimed at identifying a specific class of D-amino acids, such as D-serine, D-aspartate, and D-alanine, in order to obtain detailed information on biological significance or to investigate pathological changes due to several Damino acids [7, 8]. Moreover, the existence of proteinaceous

* Author for correspondence: E-mail: najmamemon@gmail.com
D-enantiomers of amino acids in various tissues of mammals has led to increasing demand for simple, selective, and sensitive methods for separation of enantiomeric pairs or D-amino acid in biological samples.

Quantitative chiral separations are most commonly performed using liquid chromatography and electrophoresis [1, 11]. On the other hand, simple thin-layer chromatography (TLC) is also continuously investigated and documented in the literature. TLC is reported for separation of profen isomers [12] and amino acids as their chiral derivatives onto silica gel plates [13, 14]. Though silica gel is most common supporting and stationary phase material for TLC separation, non-woven polymeric films are now emerging in this field and acquiring increasing attention of chromatographers. Nanofibers form into a very thin layer from a variety of polymers onto various supporting materials and are found to be suitable as stationary phases for the separation of amino acids. Highly efficient separation of amino acids was performed by Newsome and Olesik [15] on calcined nanofiber plates, with observed plate heights as low as $8.6 \mu \mathrm{m}$ and plate numbers as large as 1400 . Additional alignment of the nanofibers provided shorter analysis times but also wider spots. The extension of stationary phases to silica-based nanofibers vastly expands the range of mobile phases, analyte solvents, and visualization techniques, which can be used for electrospun ultra-thin layer chromatography (E-UTLC) separations [15]. Amino acids were also successfully separated using polyvinyl alcohol electrospun fibers [16]. Chiral separation of 5-(dimethylamino)naphthalene-1sulphonyl(DNS-) derivatives of some amino acids (alanine, leucine, valine, phenylalanine) D- and L-enantiomers with high-performance thin-layer chromatography (HPTLC) and pressurized planar electrochromatography (PPEC) both with $\beta-\mathrm{CD}$ as the component of the mobile phase is reported [17].

This is an open-access article distributed under the terms of the Creative Commons Attribution-NonCommercial 4.0 International License (https://creativecommons.org/licenses/by-nc/4.0/), which permits unrestricted use, distribution, and reproduction in any medium for non-commercial purposes, provided the original author and source are credited, a link to the CC License is provided, and changes - if any - are indicated. 
In view of the above knowledge, the present study is focused on the separation of chiral amino acids using $\beta$-CD incorporated into polyvinyl alcohol-glutaraldhyde (PVA-GA) electrospun fibers as a stationary phase in thin-layer chromatography.

It is hypothesized that the newly developed stationary phase would be able to separate the biologically important chiral amino acids. CDs are extensively used in chiral separations due to their unique property to form inclusion compounds with other smaller hydrophobic molecules [18]. To develop TLC sheets of $\beta$-CD incorporated into PVA-GA, electrospinning was employed to generate thin layers of polymer onto aluminum foil and was used as stationary phase for chiral separation of selected amino acids.

\section{Materials and Methods}

PVA (87-89\% hydrolyzed, average $\mathrm{Mw}=124-186 \mathrm{kDa}$ ) and glutaraldehyde (GA) were purchased from Sigma-Aldrich (USA). The $\beta-C D$ was purchased from Wako Japan, and hydrochloric acid (37\%) was from Sigma-Aldrich. Standards of serine and histidine enantiomers were purchased from Fluka. Freshly prepared Milli-Q water and deionized water were used in the entire study. HPLC-grade solvents were used throughout without further purification. Ninhydrin was used as a color developing agent for amino acids. The developed TLC sheets were scanned using an office scanner, and images were processed using ImageJ software. Smoothing of chromatograms produced by ImageJ was carried out with MS Excel using Data Analysis function.

An aqueous mixture of $10 \%$ polyvinyl alcohol (PVA) and $5 \% \beta-\mathrm{CD}$ was prepared by taking $0.015 \mathrm{~g}$ of $\beta-\mathrm{CD}$, which was dissolved in $2.7 \mathrm{~g}$ of distilled water, and the solution was stirred for $10 \mathrm{~min}$. Then, $0.3 \mathrm{~g}$ of PVA was added to the solution of $\beta-\mathrm{CD}$, and the mixture was stirred for $2.5 \mathrm{~h}$ at $80^{\circ} \mathrm{C}$. To this mixture of PVA and $\beta-\mathrm{CD}, 0.375 \mathrm{~g}$ of GA was added to accomplish crosslinking of PVA. The mixture was further stirred for $1 \mathrm{~h}$ before electrospinning was performed. Nanofibers were fabricated using an electrospinning apparatus with a high voltage power supply (Har-100*12, Matsusada Co., Tokyo, Japan). The voltage applied was $12.5 \mathrm{kV}$, and the distance between needle tip to collector was $12 \mathrm{~cm}$. Nanofibers were collected on an aluminum sheet wrapped on a rotating positive electrode. The PVA $/ \beta-\mathrm{CD}$ nanofibers were continuously collected until $2.5 \mathrm{~h}$. After the electrospinning, nanofibers were exposed to $\mathrm{HCl}$ fumes for $1 \mathrm{~min}$ to convert into crosslinked PVA/ $\beta-C D$ nanofibers. 'Water solubility test' was used to check nanofiber crosslinking. A small amount of nanofibers were put into water, insolubility confirms the crosslinking as free PVA usually dissolves in water.

A stock solution of $25 \mathrm{mg} / \mathrm{mL}$ of each amino acid (histidine enantiomers and serine enantiomers) was prepared by dissolving an appropriate amount in $0.5 \mathrm{M}$ alcoholic (methanol) hydrochloric acid. The TLC sheets were spotted with ninhydrin, which was prepared by dissolving $0.03 \mathrm{~g}$ of it in $0.3 \mathrm{~mL}$ of acetic acid and diluted to $10 \mathrm{~mL}$ with ethanol. Ninhydrin solution was sprayed using a syringe with a bent needle with an adequate distance to create a spray effect. The resolution of the spots were calculated by using the equation of resolution, $R_{\mathrm{s}}=2\left(R_{\mathrm{F} 2}-R_{\mathrm{F} 1}\right) /\left(w_{1}+w_{2}\right)$, where $R_{\mathrm{s}}$ is the resolution, $R_{\mathrm{F} 1}$ is the retardation factor of compound $1, R_{\mathrm{F} 2}$ is the retardation factor of compound 2, $w_{1}$ is the width of the first spot, and $w_{2}$ is the width of the second spot. Nicolet Avatar 330, DTGS, ZnSe ATR Crystal, Mid-IR 4000-650 $\mathrm{cm}^{-1}$, and a resolution of $4 \mathrm{~cm}^{-1}$ was used to check the surface functional groups. The surface morphology of $\beta$-CD-incorporated PVA-GA electrospun fibers was observed by employing a scanning electron microscope (JEOL JSM 6380 with a resolution of $3.0 \mathrm{~nm}, 30$ $\mathrm{kV}$, WD $8 \mathrm{~mm}, \mathrm{SEI})$.

\section{Results and Discussion}

Solutions for electrospinning need to be homogenous and well dissolved in solvents suitable to form smooth fibers. Therefore, to achieve desired conditions and morphology, polymers like cellulose acetate and PVA were tested. Incorporation of $\beta-\mathrm{CD}$ was challenging and required a long time for complete dissolution in aqueous solution. Preparation of $\beta$ $\mathrm{CD}$ into cellulose acetate was easier but stripping of fiber mat from aluminum support while developing TLC plates renders it to be investigated further. Henceforth, PVA crosslinked with GA was tested as a polymer for incorporation of $\beta-C D$. PVAGA was found to be stable in polar solvents like water, ethanol, ethyl acetate, etc. Various compositions of $\beta$-CD incorporated into the PVA-GA polymer were tested. The final composition of the polymer that provided bead free fibers was $\beta$-CD (5\%), PVA (10\%), and GA (12.5\%) in an aqueous medium. Crosslinking of PVA with GA is spontaneous, but to ensure a complete crosslink, the obtained fiber mat was exposed to $\mathrm{HCl}$ fumes for $15 \mathrm{~s}$. All other characterization and applications studies were performed on this fiber mat.

3.1. Characterization of Electrospun Fibers. Figure 1 shows the SEM images of PVA and $\beta$-CD-PVA-GA fiber mat, which are smooth and beadless fibers with an average diameter of 225 and $484 \mathrm{~nm}$, respectively. Crosslinking and inclusion of $\beta-C D$ resulted in an increase of fiber diameter and a decrease in fiber density per unit area. Also, $\beta-C D-$ PVA-GA seems to be more porous as compared to pure PVA.

Figure 2 (a) shows the FTIR spectra of PVA, peaks at $3350 \mathrm{~cm}^{-1}$ and at $2950 \mathrm{~cm}^{-1}$, which are characteristic bands for $\mathrm{O}-\mathrm{H}$ and $\mathrm{C}-\mathrm{H}$, while after crosslinking and blending $\beta$ CDs, new characteristic bands of crosslinked PVA/GA with $\beta$ CD were clearly observed in Figure 2 (b). Similar to PVA, a peak at $3350 \mathrm{~cm}^{-1}$ is attributed to $\mathrm{OH}$ from unreacted alcohols of PVA and $\beta-C D$, whereas peak at $1720 \mathrm{~cm}^{-1}$ indicates the
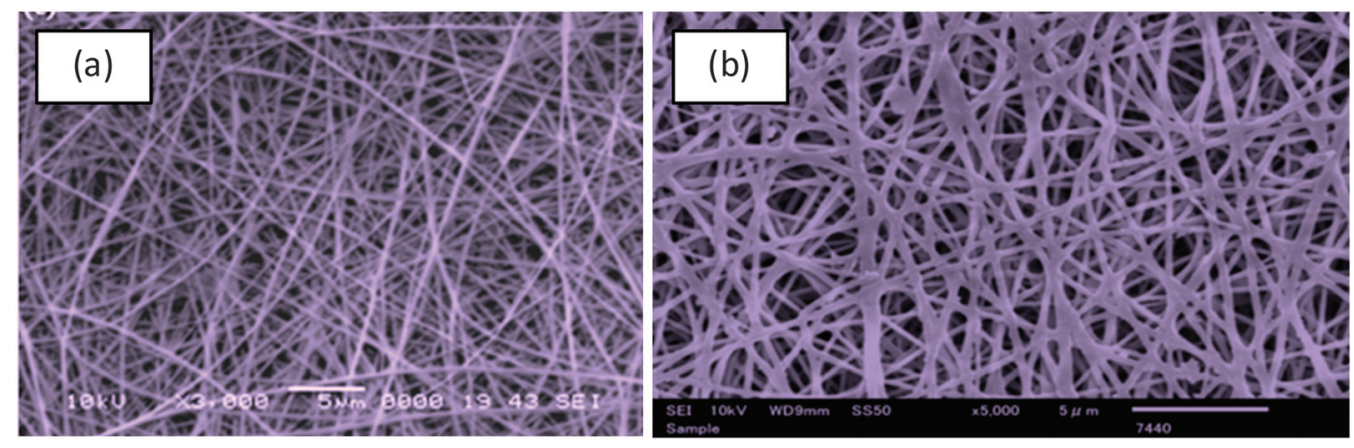

Figure 1. SEM images of pure PVA (a) and $\beta-C D / P V A-G A(b)$ electrospun fiber mat showing the fiber smoothness and thickness 


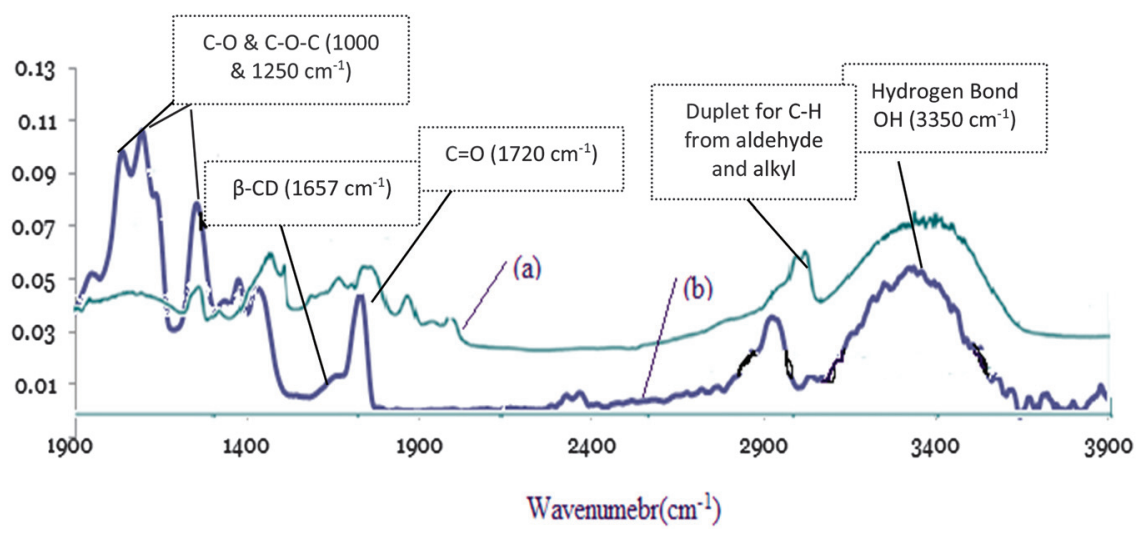

Figure 2. FTIR spectra of PVA (a) and cross-linked $\beta$-CD-PVA-GA (b), showing prominent peaks of various functionalities

incorporation of glutaraldehyde into the structure. The duplet around $2900 \mathrm{~cm}^{-1}$ is a C-H stretch of PVA and acetal formed due to the crosslinking of PVA and glutaraldehyde [19]. Multiple peaks in the range of $1000-1250 \mathrm{~cm}^{-1}$ are due to the $\mathrm{C}-$ $\mathrm{O}$ and $\mathrm{C}-\mathrm{O}-\mathrm{C}$ bonds from glutaraldehyde and the formation of ether links between PVA to glutaraldehyde and $\beta-C D$ to glutaraldehyde. Further, a small band at $1657 \mathrm{~cm}^{-1}$ is also seen, which suggests the presence of $\beta-C D$ [20]. Therefore, it may be assumed that $\beta-C D$ molecules are connected to the PVA backbone with glutaraldehyde via ether linkage.

3.2. Separation of $\alpha$-Amino Acid Pairs. A thin layer of $\beta$-CD-PVA-GA on the glass support without a binder was unstable, and cracks were observed in the thin layer after drying. However, a layer was found to be firmly stuck on a hard aluminum sheet, but the dissolution of film at some spots was observed when water was used in the mobile phase. This may be due to incomplete crosslinking of PVA-GA and $\beta$ $\mathrm{CD}$, which was improved by exposing the prepared film to fuming $\mathrm{HCl}$ for few seconds. The thickness of the stationary layer was examined to be in the range of 6 to $9 \mu \mathrm{m}$, which was further studied as the stationary phase in TLC for separation of histidine and serine isomers.

For separation of isomers, initially, ethanol, butanol, and acetic acid in various compositions were tested, but it was found that PVA-GA- $\beta-C D$ films were unstable and not compatible with acetic acid. Therefore, ethyl acetate was used to acidify the solvent system; however, the mobility of the liquid phase was limited which was increased by the addition of acetone. New quinary (penta) solvent systems in a number of compositions were tested to resolve the enantiomers of histidine and serine. Table 1 shows conditions for optimum resolution of isomers of two amino acids, whereas resolution is depicted in Figure 3. It was observed that the ethanol-to-butanol ratio was found significant in the separation of histidine isomers, which shows that the hydrophobic character is dominant in chiral separations of selected amino acids. However, contrasting behavior was seen for serine isomers, where variation in ethyl acetate content resulted in separation of serine isomers. This shows that serine, which is aliphatic amino acid, interacts through charge distribution function created at a specific acid strength onto the PVA-GA- $\beta-C D$ surface. The diffusion pattern for D- and L-isomers was found to be different; L-isomers were found to be diffused along longitude, which shows preferential binding of L-isomers with the stationary phase. In addition, the spot sensitivity was higher for D-serine, which makes it useful for its trace identification in pathological disorders.

Visual detection sensitivity of overall method for d-serine was tested by spotting various concentrations of $60-1000 \mu \mathrm{g} / \mathrm{mL}$ (Figure 4). Limit of detection (LOD) for D-serine was found.

Table 1. Optimum ternary solvent systems for resolution of histidine and serine isomers showing poor and good resolution.

\begin{tabular}{|c|c|c|c|c|}
\hline Compound & Solvent system & Composition & $R_{\mathrm{F}}$ Values & $\overline{\text { Resolution }}$ \\
\hline Histidine & Ethanol-Butanol-Ethyl Acetate-Water-Acetone & $5.5: 5.5: 4: 0.5: 1.5$ & $\begin{array}{c}\mathrm{L}=0.7 \\
\mathrm{D}=0.11\end{array}$ & 1.4 \\
\hline Serine & Ethanol-Butanol-Ethyl Acetate-Water-Acetone & $4: 5: 4.5: 0.5: 1.5$ & $\begin{array}{l}\mathrm{L}=0.4 \\
\mathrm{D}=0.8\end{array}$ & 1.6 \\
\hline
\end{tabular}

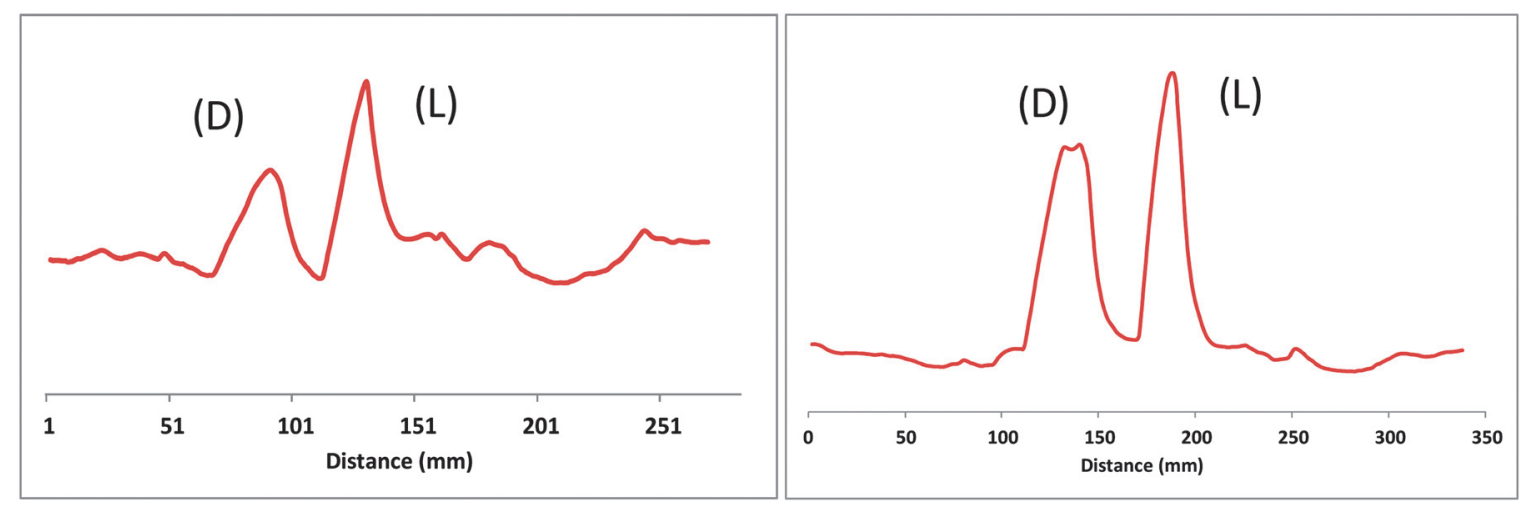

Figure 3. Chromatogram of histidine (a) and serine (b) obtained on $\beta$-CD-PVA-GA as stationary phase deposited on alumina sheet. Conditions are shown in Table-1 


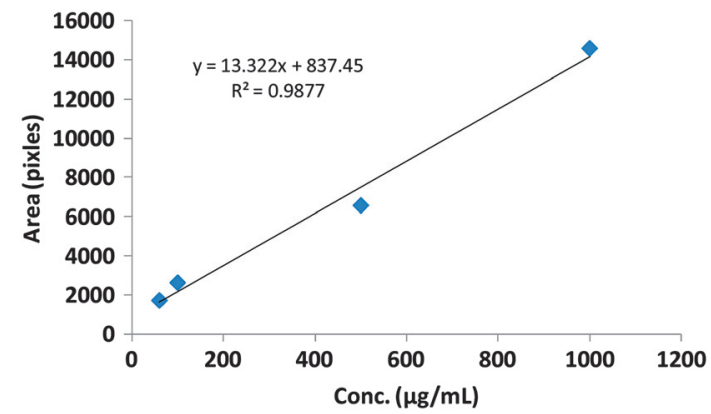

Figure 4. Linear calibration graph of D-serine. Working conditions are given in Table 1

\section{Conclusion}

Chiral selector $\beta-C D$ was linked with a PVA backbone using glutaraldehyde as a linker that was successfully electrospun to prepare stable, sticky, and non-woven fiber mats onto an alumina sheet. The sheets showed excellent chiral recognition for histidine and serine isomers as a stationary phase in their TLC separation. These TLC sheets showed potential to be studied further and can be used as a test strip for detection of D-isomers as biomarkers in biological fluids of patients with certain pathological disorders.

\section{Conflict of Interest}

All authors declare no conflict of interest related to this manuscript.
Acknowledgments. We are thankful to Prof. Muhammad Iqbal Bhanger of HEJ Research Institute of Chemistry, University of Karachi, Pakistan, for language corrections and proof reading of the manuscript.

\section{References}

1 Ward, T. J.; Farris Iii, A. B. J. Chromatogr. A 2001, 906, 73.

2 Campbell, N.; Reece, J. Biology, San Francisco, USA, Pearson/ Benjamin Cummings, 2005, p. 193.

3 Liu, Y.; Tian, A.; Wang, X.; Qi, J.; Wang, F.; Ma, Y.; Ito, Y.; Wei, Y. J. Chromatogr. A 2015, 1400, 40.

4 Miyoshi, Y.; Koga, R.; Hamase, K. D-Amino Acids, Springer, 2016, p. 3.

5 Paleček, E.; Ostatná, V. Electroanalysis 2007, 19, 2383.

6 Ilisz, I.; Berkecz, R.; Péter, A. J. Pharm. Biomed Anal. 2008, 47, 1.

7 Szökő, É.; Vincze, I.; Tábi, T. J. Pharm. Biomed. Anal. 2016, 130, 100.

8 Oyama, T.; Negishi, E.; Onigahara, H.; Kusano, N.; Miyoshi, Y.; Mita, M.; Nakazono, M.; Ohtsuki, S.; Ojida, A.; Lindner, W. J. Pharm. Biomed. Anal. 2015, 116, 71 .

9 Nakano, Y.; Konya, Y.; Taniguchi, M.; Fukusaki, E. J. Biosci. Bioeng. 2017, 123, 134

10 Fujii, N.; Takata, T.; Fujii, N.; Aki, K.; Sakaue, H. D-Amino Acids, Springer, 2016, pp. 241.

11 Ward, T. J.; Baker, B. A. Anal Chem. 2008, 80, 4363.

12 Sajewicz, M.; Piętka, R.; Pienak, A.; Kowalska, T. J Chromatogr. Sci. 2005, 43, 542

13 Nagata, Y.; Iida, T.; Sakai, M. J. Mol. Catal. B. 2001, 12, 105.

14 Bhushan, R.; Brückner, H. Amino acids 2004, 27, 231.

15 Newsome, T. E.; Olesik, S. V. J. Chromatogr. A 2014, 1364, 261.

16 Lu, T.; Olesik, S. V. J. Chromatogr. B 2013, 912, 98.

17 Polak, B.; Garbacz, P. Cur. Anal. Chem. 2015, 11, 68

18 Schneiderman, E.; Stalcup, A. M. J. Chromatogr. B 2000, 745, 83.

19 Reis, E. F. d.; Campos, F. S.; Lage, A. P.; Leite, R. C.; Heneine, L. G.; Vasconcelos, W. L.; Lobato, Z. I. P.; Mansur, H. S. Mater. Res. 2006, 9, 185.

20 Puguan, J. M. C.; Kim, H. Adv. Mater. Res., Trans Tech Publ, 2013, 